\title{
La crisis de la universidad venezolana y el imaginario de la paz (2000-2016)*
}

\section{Resumen}

En este trabajo se presenta una mirada crítica de la crisis que vive la universidad venezolana y el estudio del imaginario social de la paz. Se trata de documentar y reflexionar desde una perspectiva filosófica, histórica y sociológica, respecto a la actuación, impacto y naturaleza con que encararon las universidades venezolanas el desafío coyuntural de las políticas de Estado en el período de la Revolución Bolivariana (2000-2016); no sólo para documentar el proceso sino para ofrecer las alternativas de cara a la construcción de una paz sostenible. Metodológicamente el estudio se fundamenta en la comprensión de la historia de las mentalidades de la Escuela de Annales y el Imaginario Social de Cornelius Castoriadis (1975).

Palabras clave: Universidad, Paz, Alienación, Mentalidad, Imaginarios. pascualmoraster@gmail.com

\section{Abstract}

This paper presents a critical view of the crisis currently experienced by the Venezuelan university network along with a study of the social imaginary of peace. The purpose of the work is to document and reflect, from a philosophical, historical and sociological perspective, about the performance, impact and nature of the strategies with which Venezuelan universities faced the contextual challenge of State policies during the period of the Bolivarian Revolution (2000-2016). More than merely documenting the process, the article seeks to offer alternatives for the construction of a sustainable peace. Methodologically, the study follows the guidelines suggested by the Annales School of historiography, in particular its history of mentalities approach, and the Social Imaginary of Castoriadis, 1975.

Keywords: University, Peace,Alienation, Mentality, Imaginary.

\footnotetext{
* Artículo en colaboración con la Sociedad de Historia de la Educación Latinoamericana (SHELA).
}

POR JOSÉ PASCUAL MORA GARCÍA. Filósofo (Universidad Central de Venezuela, 1986); Magister en Gerencia Educativa (UNET, San Cristóbal, 1994); Doctor en Historia (USM- Caracas, 2002); Doctor en Pedagogía mención Innovación y Sistema Educativo (Universitat Rovira i Virgili-Tarragona-España, 2009). Profesor Titular Emérito de la Universidad de Los Andes, Núcleo "Dr. Pedro Rincón Gutiérrez". Pospresidente de la Red Internacional de Historia Latinoamericana SHELA. Posdoctorando de la Universidad Pedagógica y Tecnológica de Colombia (UPTC), bajo la dirección de la Dra. Diana Soto Arango. 


\section{Introducción}

La ciencia no piensa no es un reproche, sino que es una simple constatación de la estructura interna de la ciencia: es propio de su esencia el que, por una parte, dependa de lo que la filosofía piensa, pero que, por otra parte, ella misma lo olvida y descuida lo que exige ser pensado ahí.*

Heidegger, 1969

El estudio del imaginario de la nación ocupa un lugar privilegiado en los grupos de investigación en Venezuela, por lo menos, dos largas décadas, aunque en los trabajos de historiadores, sociólogos, científicos políticos y antropólogos el tema ha sido poco aplicado al estudio de comprensión política. En nuestro caso, es una línea de trabajo que hemos iniciado en textos como Imaginario Social Bolivariano (2006), "El neonacionalismo bolivariano" (2006), "Rómulo Betancourt e imaginario Político" (2008). En la LXIV Convención Anual de la Asociación Venezolana para el Avance de la Ciencia (AsoVAC) (2014) se manifestó la posición acerca de la paz como imaginario social, en el cual hemos dado cuenta del proceso de construcción de los imaginarios sociales por parte del gobierno actual. La utilización de los símbolos de la nación y su refundación han sido una constante al intentar imponer nuevas representaciones con nuevos símbolos de la nación.

Desde el punto de vista metodológico nos apoyamos en la historia de las mentalidades y de las representaciones, que tienen sus antecedentes al interior de la tradición historiográfica de la Escuela de Annales (1929), que trajo el Dr. Federico Brito Figueroa, luego de su formación en México, a Venezuela y que ha sido profundizada por el Dr. Reinaldo Rojas. Hoy como herederos de esa vertiente historiográfica entramos en el nivel de la superestructura jurídico-política e ideológica venezolana para analizar el imaginario social bolivariano como acicate de la paz.

Después del largo proceso de Independencia (1810-1830), la paz pasa a ser parte de un imaginario social fortalecido en el inconsciente colectivo, que se consolida gracias a ese imaginario social que tiene en Bolívar la representación mayor. El imaginario social bolivariano es el lugar donde anidan las representaciones que alimentan la paz de la nación. Desde entonces el bolivarianismo ha sido por antonomasia un espacio de representación nacional, pero también, y más importante, ha sido el instrumento usado por los gobiernos para manipular al pueblo: desde los conservadores censitarios de José Antonio Páez, la autocracia ilustrada de Antonio Guzmán Blanco, la larga tiranía de Juan Vicente Gómez, la dictadura militar de Marcos Pérez Jiménez, hasta la experiencia democrática partidista y representativa, 1998. Pero sobre todo, ha sido fuente de manipulación de la nación con la llegada de Hugo Chávez en 1998. Todos, sin excepción, han basado sus proyectos políticos sobre un régimen emocional, de adhesión ciega a una supuesta transformación "bolivariana" que nunca llega. Cada nuevo gobierno se erige en voz profética invocando a Bolívar como el semidiós que vendrá a salvar a su pueblo, lo cual maceró el culto a Bolívar -componente del imaginario nacional, para despertar emociones y adhesiones que en su origen son ficciones discursivas, pero que dependiendo de la habilidad retórica del gobernante de turno crea patrones de conducta que confunden al pueblo e incitan a la acción.

En Venezuela, casi cualquier discusión sobre el modo de gobierno y los planes de la nación remiten a una discusión sobre el uso del imaginario bolivariano. Pero es un imaginario fundacional que no siempre está libre de causar problemas. El imaginario social ha terminado por ser una excelente fuente para legitimar gobiernos y prolongar la agonía como pueblo. En nombre del imaginario bolivariano se legitima el dispositivo de poder en manos de militares, y les está permitido interrumpir las libertades democráticas para supuestamente profundizar en ellas. Igualmente, se apela a la crítica de los discursos hegemónicos imperiales, invocando supuestas invasiones, especialmente del norteamericano para justificar el fracaso de las políticas de Estado.

También recuperamos en nuestro trabajo el estudio de los imaginarios desde la óptica de la antropo- 
logía, especialmente, en la interpretación de Gilbert Durand (2000), que se remonta a los años sesenta cuando publicó Las estructuras antropológicas de lo imaginario. Heredero de la tradición de Mircea Eliade, Gaston Bachelard, Claude Lévi-Strauss, y Paul Ricoeur, ha sabido conciliar el estructuralismo figurativo y las corrientes hermenéuticas.

La investigación de los imaginarios no tiene nada que ver con ficciones, como comúnmente se entiende. Lo imaginario alude a las imágenes mentales y visuales organizadas por la narración mítica de cada individuo, de cada pueblo, de cada nación. El enfoque tiene que ser interdisciplinario, por eso, tendríamos que decantarlo desde el análisis de la memoria (Halbwachs, 1994), de la memoria colectiva (Bloch, 1994), del "utillaje mental" (Febvre, 1993), de las formas simbólicas (Cassirer, 1972), el imaginario social (Castoriadis, 1975) y sus respectivas memorias o mentalidades; en fin, no puede abordarse en forma plana. Como dice Evelyne Panthagean (1996) la historia de lo imaginario es una cuestión demasiado amplia, pues sus dominios abarcan de la historia de las religiones a la historia de la literatura.

\section{El imaginario de la paz y el rol de la universidad venezolana}

Atacar a una sola criatura humana es atacar a esos poderes divinos; $y$ por lo tanto, el daño se hace no sólo a ese ser, sino a través de él, a toda la humanidad.

Chopra

Hace algunos años el filósofo alemán Martin Heidegger sorprendía al mundo científico con la afirmación según la cual: "la ciencia no piensa", para significar que necesita de la filosofía como acicate para llevar a cabo esa responsabilidad de acompañamiento epistemológico, teleológico, ontológico y bioético. Por alguna razón hasta el siglo XVIII la ciencia y la filosofía fueron conceptos intercambiables. Ya en 1963, Karl Paul Feyerabend había afirmado también que la ciencia no es neutra, que la ciencia también es política. La supuesta neutralidad valorativa de la ciencia fue develada, no hay ciencia neutra, la ciencia también es política. Hacer ciencia implica tomar una posición, la ciencia también es comprometida. Lo importante es preguntarnos: 
¿comprometida con qué? ¿Aliada con quién? Ya lo decía Jean Paul Sartre, en El existencialismo es un humanismo, aun los que no eligen ya han elegido; eligiéndome, elijo al hombre. No hay elecciones particulares, la elección personal compromete la elección del género humano.

No es un secreto que la ciencia ha sido puesta al servicio del poder hegemónico mundial. De hecho, el poder "anglobalizador" diseña cómo debemos comportarnos y determina nuestras maneras de ser y de sentir. Pero al mismo tiempo que debemos estar atentos a las culturas dominantes para construir un poder contra hegemónico desde nuestros países, también debemos mirar sobre nuestra casa. La hegemonía se reviste para ejercer la dominación al interno de nuestros países; así las cosas, la producción de ciencia y tecnología en Venezuela vive determinaciones hegemónicas de parte de las políticas de Estado, cercenando las posibilidades competitivas. Por eso debemos estar atentos a las agendas gubernamentales ocultas que limitan y controlan la producción científica en Venezuela. Pero sobre todo la libertad de conciencia.

\section{Los investigadores, como el brazo pensante de una sociedad, son garantes de los procesos de paz, y ese debe ser nuestro compromiso; ya lo decía Antonio Gramsci, al hablar del "Intelectual Orgánico."}

Este proceso ocupará nuestro tema al señalar que las políticas públicas que atentan contra la educación superior en Venezuela y afectan el imaginario social de la paz. Los investigadores, como el brazo pensante de una sociedad, son garantes de los procesos de paz, y ese debe ser nuestro compromiso; ya lo decía Antonio Gramsci, al hablar del "Intelectual Orgánico." Los intelectuales no solo se limitan a contemplar la vida social, como dijera Karl Marx en la tesis XI sobre L. Feuerbach, sino que son la autoconciencia de la sociedad; apuntan “a buscar la relación entre la organización y las masas como una relación entre educadores y educados, que se invierte dinámicamente al papel de los intelectuales -en el seno del intelectual orgánico, la conquista y transformación de los aparatos del Estado- para crear las condiciones de esa nueva hegemonía y la transformación de la sociedad civil".1

La ciencia en Venezuela vive uno de los momentos más difíciles en la historia republicana, pues se ha sacrificado a la generación con mayor capital intelectual de los últimos 50 años. Los grupos de investigación y los investigadores de alto impacto han tenido que migrar para poder seguir haciendo ciencia, ya que no es posible hacerla desde sus universidades de origen, dado el bajo aporte que llega a la universidad para realizar las investigaciones y proyectos. En ese sentido, decimos que la ciencia ha sido secuestrada por los poderes de turno, y en su defecto, se busca tutelar y adoctrinar.

La ciencia no es neutra, y eso lo conoce muy bien el poder. Por eso, diseña planes para controlar las becas, estudia cuáles son los países que interesa para enviar a los becarios, más por razones ideológicas que científicas, y establece las agendas de formación de los investigadores limitando la investigación abierta.

Lo cierto es que nos sentimos secuestrados en nuestra propia casa. En el Congreso Internacional de la Sociedad de Historia de la Educación Latinoamericana, SHELA, que se realizó en Puerto Vallarta-México (2014) y Guatemala (2016) no pudieron asistir colegas de Venezuela porque no había ni pasajes ni divisas; esa es la triste realidad. En palabras del Dr. Iván Hurtado León de la Universidad de Carabobo "esa ha sido una constante."

El pretendido concepto de ciencia endógena difundido por los entes gubernamentales ha seccionado la posibilidad de validar nuestros conocimientos en el contexto internacional, posición errada y aldeana, pues la ciencia y la epistemología son universales y no parroquianas. El conocimiento y la ciencia no se validan en forma endógena, sino externamente; sumándose a este el hecho de que son las redes académicas nacionales e internacionales las que en definitiva acreditan a los investigadores reconocidos. El sistema de par académico lo acredita la comunidad científica internacional. Es el consenso entre la producción científica.

La universidad ha perdido el escenario por antonomasia de la producción de ciencia y tecnología. La 


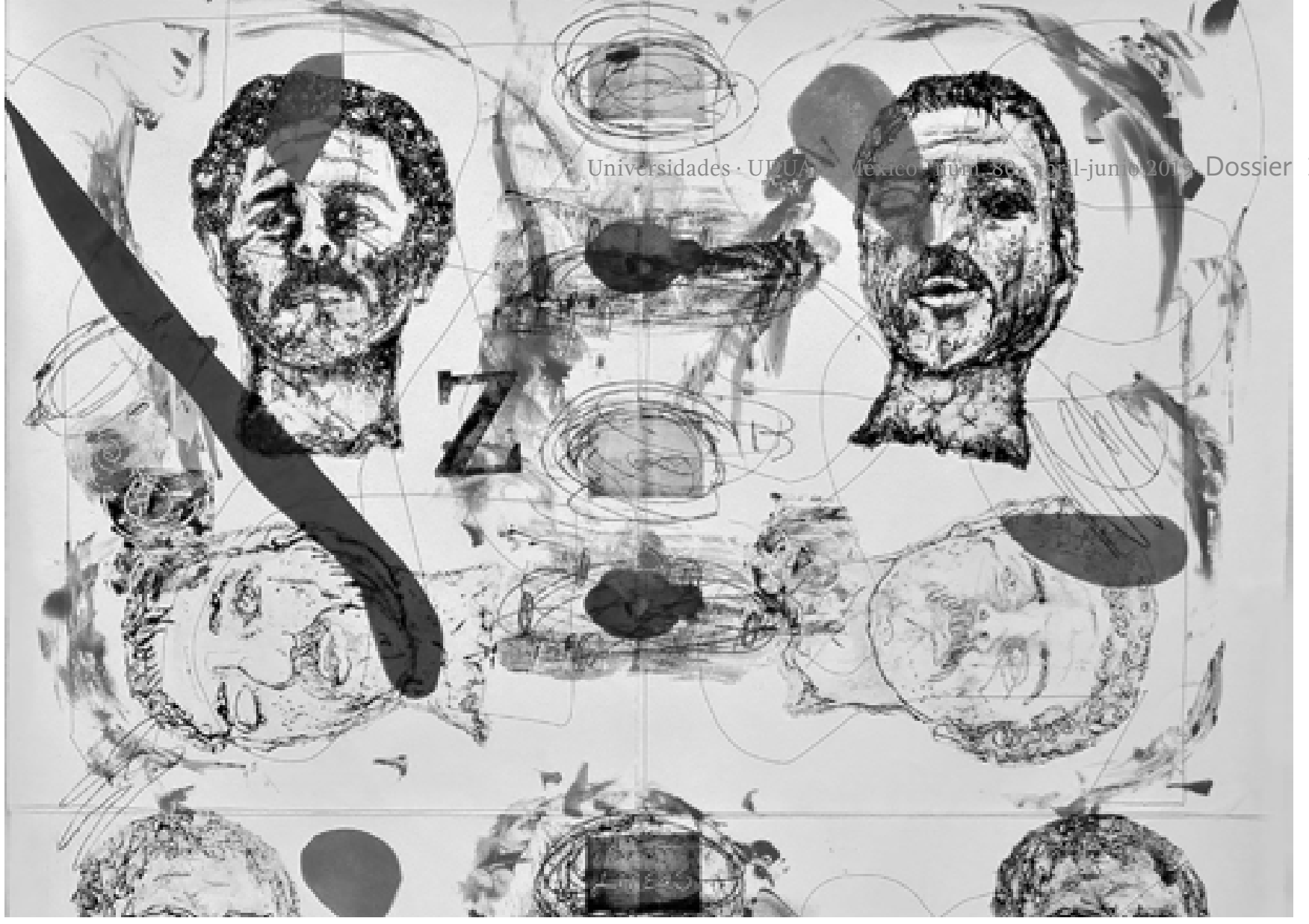

Elina Chauvet, Afilando machetes, colografia/mixta/papel RFK, $111 \times 112$ cm, 2009.

universidad ya no decide a dónde enviar a sus generaciones de relevo; hoy es cada vez más difícil e imposible porque estamos controlados por una psicología del hambre que administra la ansiedad según el nivel de conflictividad, nos hemos convertido en "bachaqueros del conocimiento" $\mathrm{y}$ cuasi refugiados del conocimiento científico, y quizá la peor de todas de las alineaciones: somos cómplices de una indefensión inducida, en la que hemos terminado siendo cómplices del represor, una especie de Síndrome de Estocolmo en lo académico, en el que nos aliamos con el secuestrador para legitimar políticas de Estado que limitan nuestras capacidad de logro y mutilan el pensamiento abierto.

Desde 1945 se generó en el inconsciente colectivo una matriz mental que ha sido insuflada en el mismo inconsciente colectivo. ${ }^{3}$ Esa herencia mental dependiente del Estado, de ver al Estado como el Papá Noel de los venezolanos. En consecuencia nos hemos acostumbrado a esa suerte de "buenismo social", en el que podemos decir con Rafael López-Pedraza (2000) que jugamos a la «cultura de piñata», vivimos una histeria hebefrénica, en donde se exagera la histeria de lo infantil. Es la reproducción de la conducta irresponsable que parece masificarse. Recientemente, un supuesto deportista asistió a unas olimpiadas de invierno sin haber pisado en su vida la nieve. Lo llamé en una nota de opinión:
Síndrome "Solano" porque persigue a los venezolanos que migran pensando que pueden hacer lo mismo que en Venezuela. He visto en oficinas de migración a muchos jóvenes esperando visa y sin ninguna educación cívica. Buscan oportunidades, pero perseguidos por el síndrome del "solanismo", que piensan que sin excelencia se pueden encontrar los éxitos, que piensan que sin esfuerzo se logra el reconocimiento. Esa herencia de un "buenismo social" históricamente escalonado en los andamios mentales del venezolano promedio nos hace dar pena ajena. No solo necesitamos cambios de gobierno, sino cambios, en lo que López Pedraza denominaba "cambio de la cultura hebefrenética", que sigue soñando con golpes de suerte y reforzando la mentalidad petrolera. La verdad, sentí mucha pena por ver connacionales buscando visas, pero no con las mejores notas sino con los mejores tatuajes y estereotipos postmodernos. Esa no es la Venezuela de la fuga de talentos sino el efecto síndrome del "solanismo" que nos asusta. Luego descubrimos que era de las filas de los "gobierneros", otra burla del maltratado imaginario que proyectamos los venezolanos en el exterior.

Incluso se ha pretendido silenciar al mundo académico señalándose que se es apátrida y no defensor del nacionalismo, si se dicen las verdades, nada más falso. ${ }^{4}$ Es inminente que el investigador salga de la zona de 
confort para asumir una conciencia crítica y moralizante; con una ética de la no violencia, con una ética de responsabilidad social gadameriana para que sea actor de la esperanza. El mundo académico no debe caer en la trampa del nacionalismo metodológico pregonado por el Estado mega-actor; "para poner un ejemplo: si la política y la sociedad se deslimitan y desestatizan el resultado es que lo que se considera 'nacional' e 'internacional' ya no puede separarse y lo aparentemente igual, o sea, el interior sagrado del espacio de poder del Estado nacional se convierte en campo de intervención directa de actores, organizaciones y acontecimientos críticos internacionales, supranacionales y trasnacionales". Ya no se puede suponer que, por ejemplo, las desigualdades y conflictos nacionales sean analizables exclusivamente desde la óptica nacional; ya no se puede partir de que los actores, temas, burocracias y autoridades de la política interior coinciden con los actores, temas y burocracias y vías de influencia que la mirada nacional y el nacionalismo metodológico -en tácito acuerdo- dan por supuestos. La Nueva Teoría Crítica descubre conceptualmente que los clásicos límites entre política interior y exterior se borran y mezclan, que las diversas disciplinas de las ciencias sociales, como la política internacional y la teoría del gobierno nacional se liberan del dogmatismo de la mirada nacional y se asocian, y que la teoría del gobierno tiene que reescribirse desde el ángulo cosmopolita (Ulrich, 2004, 82). No podemos los investigadores apoyar políticas que vulneren nuestra economía, porque simplemente no podremos sobrevivir. El reto es: o tenemos un sueldo competitivo en el contexto internacional, al menos con los vecinos latinoamericanos, o estamos destinados a desaparecer; porque el mundo académico no es de competencias a medias, es un mundo de la excelencia sostenible.

El mandamiento cartesiano del "Pienso, luego existo" pareciera ser una entelequia que no responde al mundo de hoy; ya el filósofo brasileño Leonardo Boff nos apuntalaba que en América Latina el "yo pienso, luego existo" debe ser sustituido por el "yo siento, luego existo". Los latinoamericanos somos más sentimiento que razón, y ese reto está en la palestra.

Nuestro llamado a invocar el imaginario social de la paz pasa por conectar ese imaginario social macerado históricamente como emancipación y no como 
alienación. El imaginario social bolivariano debe salir de su zona de confort amparado en el "buenismo social" que tutelan la moral social amparada en la psicología del hambre. Porque en nombre de la paz también se subyuga, en nombre de la paz también se adormecen las conciencias, en nombre de la paz se han construido los imperios, en nombre de la paz también se impone la resignación; compartimos con el historiador francés Jacques Le Goff, recientemente fallecido, que "se debe actuar de modo que la memoria colectiva sirva a la liberación, y no a la servidumbre de los hombres"

\section{El mandamiento cartesiano del "Pienso, luego existo" pareciera ser una entelequia que no responde al mundo de hoy; ya el filósofo brasileño Leonardo Boff nos apuntalaba que en América Latina el "yo pienso, luego existo" debe ser sustituido por el "yo siento, luego existo".}

En octubre y noviembre de 2014, realicé una pasantía académica internacional en México, en Guadalajara y Puerto Vallarta, haciendo grandes sacrificios económicos familiares, pues debía asistir como presidente de la Red Latinoamericana de Historiadores SHELA, al congreso internacional de la Shela. En ese ínterin, acompañé a una marcha estudiantil en Guadalajara, en Jalisco, México en solidaridad humanitaria por los 43 estudiantes de la Normal de Ayotzinapa, y observé que una de las vallas señalaba: "YO PIENSO, LUEGO ME DESAPARECEN". Esa paradoja se ha democratizado en nuestros países; y los estudiantes son los primeros en sufrir la extraña suerte en la que devino la máxima cartesiana, enunciada por el filósofo René Descartes. El "YO PIENSO LUEGO EXISTO" es ahora "YO PIENSO, LUEGO ME DESAPARECEN".
Guardando todas las distancias con el problema de fondo que vive el hermano pueblo mexicano, debemos decir que a nuestros estudiantes venezolanos también se les cercenó la esperanza y se les arrancó de la vida entre los años 2014-2017 por disentir de las políticas de Estado ${ }^{5}$; tenemos que reconocer que Venezuela está enferma. Está enferma por un diálogo amañado, está enferma de crisis de institucionalidad, pero también está enferma de aquellos que quieren una salida violenta. Apostamos a la paz y rechazamos la violencia, pero al mismo tiempo apostamos por una democracia en donde la razón de ser no la determine la virtud armada sino la virtud civil, por eso, no podemos silenciar los anhelos de una generación que clama sus derechos.

El imaginario social (Castoriadis, 1975) de la paz en Venezuela debe ser un resultado de una mentalidad colectiva; "no es obra de un individuo en particular, jefe o legislador, ni de un conjunto contractual de individuos. Es obra de un colectivo anónimo e indivisible, que trasciende a los individuos y se impone a ellos. El imaginario social provee a la psique de significaciones y valores, y a los individuos les da los medios para comunicarse y les dota de las formas de la cooperación. Es así, no a la inversa". ${ }^{\circ}$

El imaginario social de la paz en Venezuela debe invocar el ejemplo dejado por Bolívar, quien fue capaz de invocar primero al ciudadano antes que al guerrero: "yo quiero ser ciudadano para ser libre y para que todos lo sean. Prefiero el título de ciudadano al de Libertador, porque este emana de la guerra, aquel emana de las leyes. Cambiadme, Señor, todos mis dictados por el de buen ciudadano".

Bolívar pensó en una universidad que no estuviera subordinada a los monarcas, ni a la nobleza, ni al clero, ni a los poderes locales, ni al caciquismo, ni al poder económico. Por eso, inició el poder de las transformaciones eliminando la figura del CENSOR REGIO, quien revisaba las tesis con espíritu inquisidor para que no se mencionaran los libros ni los autores que no convenían a la estructura de dominación.

Igualmente, eliminó las discriminaciones que reservaban la formación universitaria a las clases política y económicamente pudientes, superándose los criterios moralistas que discriminaban a los que no tenían un legítimo nacimiento. El ideal bolivariano perfilaba una universidad con nuevas cátedras, con nuevos laborato- 


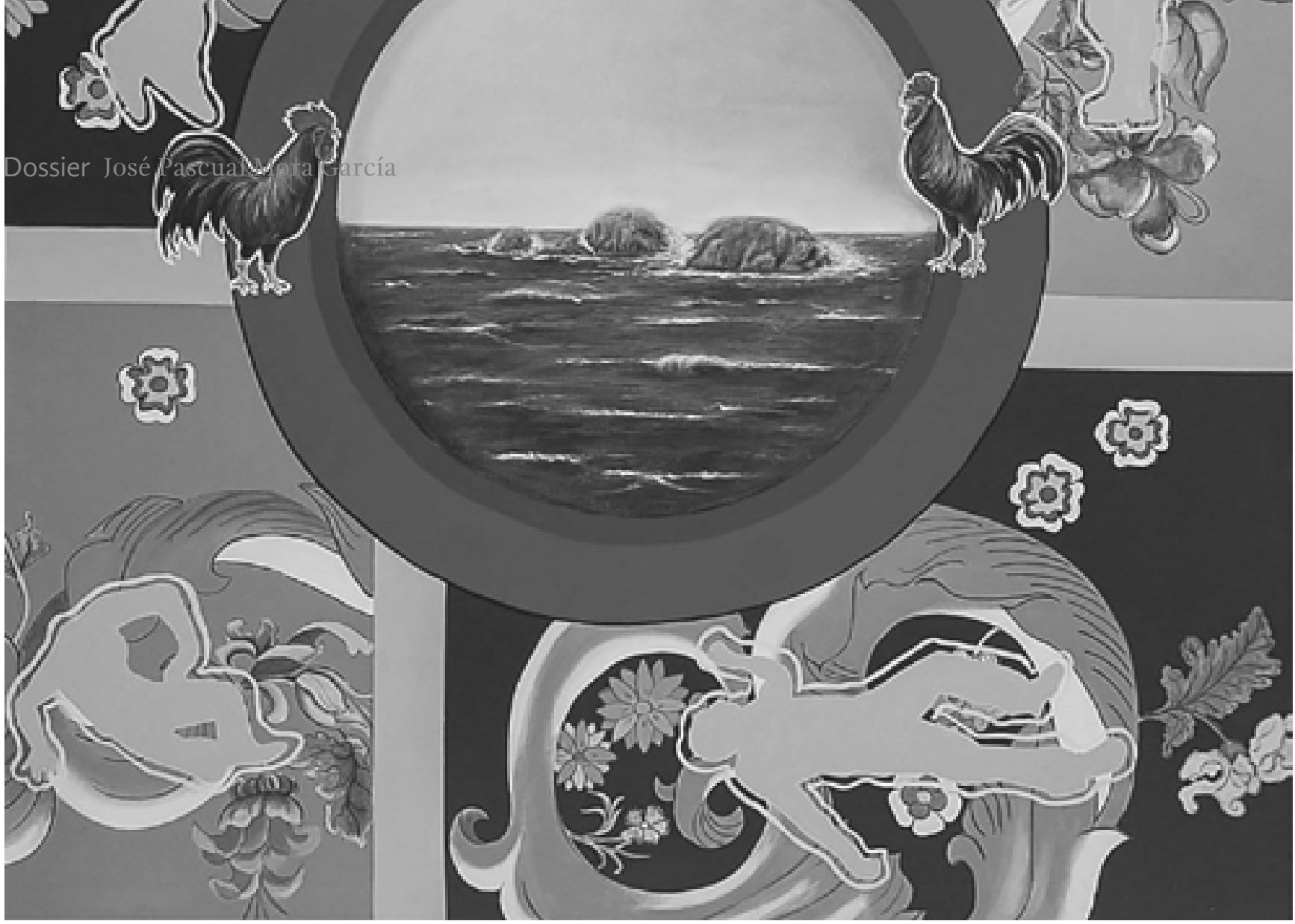

Elina Chauvet, Los Tres Gallos, mixta/tela, 140x145 cm. 2007.

rios, con amplitud de pensamiento a todos los credos, sin que el color de la piel fuese obstáculo para recibir los títulos académicos.

Pero hay que decir, igualmente, que Bolívar no utilizó tampoco la universidad. Nunca sintió complejos por haber tenido una formación fundamentalmente de autodidacta, tampoco regateó fondos para la universidad. Y no hay ni un solo documento en donde Bolívar haya utilizado la universidad para recibir halagos o lisonjas, o para pretender írritamente borlas doctorales.

Fue aquel 24 de junio de 1827, cuando nació la Universidad Republicana, al ser sancionados por el Libertador los primeros Estatutos o Constituciones. La Universidad Republicana nació de la mano de un gran civilista, como fue el doctor José María Vargas. Pero al mismo tiempo, los Estatutos Republicanos revelaron el espíritu civilista del Libertador, ya que en ninguna de las cláusulas se reservaron consideraciones especiales como Jefe de Estado. Por ello, debemos reconocer en Bolívar el esfuerzo pionero por dar a la universidad la autonomía, dejando la elección de las autoridades universitarias en manos del claustro de profesores y dotando la institución de un patrimonio económico. Desgraciadamente, el ideal bolivariano fue violentado y puesto al servicio de las montoneras insubordinadas, el caudillismo bárbaro, la autocracia militar, las dictaduras, y un sistema democrático aliado con una partidocracia perversa.

Bolívar fue un precursor de la universidad popular y democrática; dictaminó que en su seno se admitiría a todo estudiante, sin tomar en cuenta discriminación de color de piel, ni edad, ni traba económica. Bastaba saber leer y escribir correctamente para ser admitido como universitario.

Exceptuó al estudiantado del servicio militar, como una demostración fehaciente del deslinde entre el militar y el ciudadano. El poder de las armas es uno, y el poder de las leyes y el saber es otro. El mérito de Bolívar es doble, pues no solamente deslinda entre el hombre de las leyes y el hombre de la guerra, sino que deslinda entre ciencia política y ciencia militar; aspectos que para la época estaban íntimamente unidos por la influencia de Napoleón, quien encarnaba la unidad de ambos poderes. Antes de la profesionalización de la ciencia militar, la misma persona podía estar simultáneamente representando ambos estados. Hoy por hoy, es imposible, no sólo por razones de índole personal sino por razones de principios; la intercambiabilidad entre el hombre de Estado y el Soldado ha terminado definitivamente.

En este sentido Bolívar se alinea en la tradición de los más grandes teóricos del pensamiento militar, 
al deslindar entre el poder político y el poder militar. Llegando incluso a conclusiones similares a las del más grande teórico militar del siglo XIX Karl von Clausewitz, quien escribió De la Guerra (1831) mientras era director de la Academia de Guerra. Clausewitz “expresa que la advertencia militar al hombre de Estado respecto de que perciba cuidadosamente los límites de su fuerza militar al formular metas y compromisos. Pero al final, la política debe predominar. La política puede por cierto, 'adoptar una orientación errada, y preferir promover fines ambiciosos, intereses privados o la vanidad de los gobernantes', pero eso no le concierne al militar. Debe suponer que la política es 'la representación de todos los intereses de la comunidad entera', y obedecerla como tal. Al formular la primera fundamentación teórica de la profesión militar, Clausewitz, también contribuyó a la primera justificación del control civil". ${ }^{8}$

La búsqueda de la virtud civil no puede ser obligada, debe construirse lentamente con la educación del pueblo y el cultivo de los valores democráticos; no es por decreto o por imposición, como lo pretendió el jacobinismo al intentar imponer la virtud necesaria para crear al ciudadano de la sociedad democrática utilizando el terrorismo del Estado.

El imaginario social debe seguir el ejemplo de Bolívar; la virtud armada debe estar sometida a la virtud civil, so pena de desvirtuar el sueño democrático. El imaginario de la paz en Venezuela debe pasar por sentido emancipatorio del ser humano, y no con visiones alienantes y cobijadas por la "moral de esclavos hegeliana" impuesta por el poder de turno.

Las políticas públicas en materia de la educación superior ${ }^{9}$ serán el tema en esta segunda parte. Paradójicamente cuando más se diseñaron políticas de inclusión y se crearon casi 30 nuevas universidades, en ese mismo momento, se diseñó por partida doble un plan estratégico para infravalorar las universidades públicas de alto impacto; simplemente por no estar sujetas al tutelaje académico (Mora García, 2012,190 y 191). La historia de la educación no es neutra y por eso consideramos que también debemos expresar la mirada contra hegemónica frente a las políticas públicas que han desmontado el aparado de producción de conocimientos en la universidad venezolana. Y decimos desmontado porque la crisis y falta de apoyo a la investigación han destruido buena parte de los grupos de investigación e inducido a la fuga de talentos a otros países, ${ }^{10}$ mutilando las esperanzas de las generaciones de relevo para insertarse en el difícil mundo competitivo global.

Lo cierto es que desde el 2010 se buscó minar la productividad de los investigadores y las universidades, así como los programas que servían de visibilidad para mostrar la calidad y excelencia de la productividad académica, con el argumento peregrino de que eso era ciencia burguesa, y que se debía masificar la ciencia.

\section{II \\ Las políticas públicas y la crisis de la investigación en la universidad venezolana ${ }^{11}$}

Nuestra línea de investigación se inició en el año 1997, y el resultado fue presentado como Tesis Doctoral en Pedagogía en la Universidad Rovira i Virgili (2009), Tarragona, España.

En diciembre de 2010, la Asamblea Nacional cometió un genocidio académico cuando se eliminó la data histórica de 20 años del Programa Sistema de Promoción al Investigador (SPI-PPI), programa que establecía el ranking de los investigadores reconocidos nacionalmente y que había sido elaborado sobre la base del modelo mexicano en 1990. A pesar de que había sido un programa exitoso, pues había experimentado un crecimiento positivo en sus casi 20 años, pasando de 741 investigadores (1990) a 6791 para el 2009; no obstante, se optó por eliminarlo.

En enero de 2011, el Ministerio P. P. de Ciencia y Tecnología convocó a un nuevo Registro Nacional de Innovadores e Investigadores (RNII), pero los resultados habían menoscabado la tradición de la evaluación de la investigación generando inconformidad por el sesgo ideológico. Aun cuando en términos cuantitativos pareciera que hubo un crecimiento al incorporar los llamados "innovadores", lo cierto es que sirvió para aumentar estadísticas sin densidad. Ya que el nuevo sistema sólo convalidó a los investigadores eméritos, pero dejó por fuera a los investigadores en los niveles I, II, III y IV que habían hecho carrera por más de 20 años. Los resultados los estimamos como un crecimiento negativo en lo cualitativo, si tomamos en cuenta que una tercera parte de los anteriormente clasificados no 
aplicaron al PEII, además de una campaña de infravaloración hacia los investigadores destacados, que vieron cada vez más menguadas las posibilidades de hacer investigación de punta en nuestras universidades.

Las reducciones presupuestarias y limitaciones en las políticas de financiamiento de los programas de los Consejos de Desarrollo Científico Humanístico Tecnológico y de las Artes (CDCHTA) ${ }^{12}$ marcaron la pauta del declive de la productividad en la universidad venezolana, llegando a ser cero el apoyo a programas de viajes al exterior y organización de congresos internacionales; el diferencial cambiario destruyó la opción real. ${ }^{13}$

$\mathrm{Y}$ las amenazas se hicieron alarmantes cuando en la fallida ${ }^{14}$ Ley de Educación Universitaria (LEU-2010) se eliminaba prácticamente el rol de docente investigador autónomo para pasar a un modelo en donde el Estado ejerciera el tutelaje de la investigación en la universidad; en el Art. 28 se enunciaba que la investigación estaría bajo la responsabilidad de un ente denominado Consejo Territorial de Transformación Universitaria: "Cada Consejo Territorial de Transformación Universitaria tendrá un Centro de Estudios Territoriales definido como un espacio abierto académico-comunitario para la integración de saberes y conocimientos, que potencie la vinculación social y oriente la acción de las Instituciones Universitarias mediante la formación, la creación intelectual, la interacción con las comunidades y el desarrollo socio productivo, en función de la concreción de redes de proyectos para el desarrollo integral del Eje Territorial correspondiente. En cada Centro de Estudios Territoriales, participarán los núcleos académicos de las instituciones de educación universitaria, las misiones, las organizaciones del Poder Popular, organismos y entes del Estado encargados de investigación, planificación y gestión de proyectos."

La doble moral opera como mecanismo de acción. En teoría la LEU está vetada, pero en la práctica se aplica. Lo dramático es que a pesar del veto presidencial de la LEU-2010 se hace una aplicación "blanda", lo cual no solo es inconstitucional sino inmoral porque no contempla más que el "dedo del príncipe" ejerciendo el poder. Con la intervención "blanda" en las decisiones de los CDCHT de las universidades, la investigación queda bajo el dominio del gobierno y en maridaje con las políticas de turno; violentándose uno de los principios fundamentales de la investigación como es la investigación abierta. El derecho obtenido por los investigadores en nuestras universidades fue menoscabado; inicialmente, se redujo el financiamiento de viajes al exterior a dos años (desde 2008), e incluso se introdujo una jurisprudencia para solicitar celestinamente a la Vicepresidencia de la República autorización para optar a un pasaje o subvención a un investigador reconocido. Celestinamente porque los investigadores eran revisados en una base de datos del Estado para controlar si eran afectos al sistema o no.

\section{...debemos reconocer en Bolívar el esfuerzo pionero por dar a la universidad la autonomí, dejando la elección de las autoridades universitarias en manos del claustro de profesores y dotando la institución de un patrimonio económico.}

Con el argumento del desarrollo de una supuesta ciencia endógena se limitó la participación de los investigadores reconocidos. Desconociéndose que necesariamente la ciencia se valida externamente, sumándose el agravante de que son las redes internacionales las que en definitiva acreditan a los investigadores reconocidos de alto impacto. La participación de los investigadores en revistas indexadas en Scopus y el Índice h en Google Académico se fue viendo mermada por las dificultades de publicación y los incentivos para actualizar conocimientos.

Para el análisis del record histórico de la historia del Programa de Promoción al Investigador (PPI), seguimos el trabajo de Daissy Marcano y Mauricio Phelan (2009), que en 20 años nos arrojan los siguientes datos: de 741 investigadores en 1990 a 6791 para el 2009, según la información oficial de la ONCTI. ${ }^{15}$ 
La paradoja se multiplica, pues aun cuando no se retrocedió, el programa fue intervenido y cerrado en 2010. En el año 2007, Daissy Marcano, entonces presidenta del Observatorio Nacional de Ciencia y Tecnología (ONCTI), presentaba en el VII Congreso Iberoamericano de los Indicadores en Ciencia y Tecnología un balance a la comunidad internacional (São Paulo, Brasil), en el que señalaba un balance positivo. Incluso en términos de investigadores, por habitantes se experimentaba un crecimiento, y nos ubicaba entre los países de América Latina con una proyección en ascenso por cada 10.000 habitantes.

Venezuela reportaba para el año 2007, un total de 5222 investigadores reconocidos por el PPI. En la versión de la Daissy Marcano, presidenta de ONCTI, en el VII Congreso Iberoamericano de los Indicadores en Ciencia y Tecnología, realizado en São Paulo entre el 23 y 25 de mayo de 2007, nos señala: "En el período 90-98 la tasa de crecimiento promedio anual fue de $5,5 \%$ y el crecimiento total del mismo período fue de $51,3 \%$. En el período 1999-2005 la tasa de crecimiento promedio fue de $10,6 \%$ y el crecimiento total del mismo período fue de $85,4 \% " 16$ (ver cuadro 1 ).

Los indicadores bibliométricos, según el SCI (2002-2006), una metodología que nos permite conocer el sentido teleológico de los productos (dónde van los artículos, cuáles son, cuál es su impacto, quién, cuándo, y dónde pública) colocaba a Venezuela entre los primeros 5 lugares de las publicaciones registradas en América Latina, tomando como referencia el Science Citation Index (ver cuadro 2).

Ese logro fue cambiado radicalmente en los últimos 10 años, demostrándose el error que significó sacrificar los aportes a la investigación de alto impacto. Aun cuando estábamos lejos, el índice de investigadores por cada 10.000 habitantes era aceptable para nuestros países. Al comparar, con los índices de algunos países de América Latina, Europa y Asia: Chile tiene 5 investigadores por cada 10.000 habitantes; Brasil tiene 6 por cada 10.000 habitantes, España tiene 7 por cada 10.000 habitantes; Alemania tiene 32 por cada 10.000 habitantes; y Japón tiene 40 por cada 10.000 habitantes. Al respecto comenta Daissy Marcano: "Sin duda se puede concluir que el PPI ha contribuido de manera significativa al crecimiento del número de investigadores en las instituciones del país; sin embargo, sólo se cuenta con 0,42 investigadores acreditados en el PPI por cada 10.000 habitantes de la población económicamente activa". ${ }^{17}$

Ya para el año 2007 las cifras eran totalmente diferentes (ver cuadro 3).

El nuevo programa de evaluación de los investigadores en Venezuela, llevado a cabo entre marzo y junio de 2011 por parte del Observatorio Nacional de Ciencia, Tecnología e Innovación (ONCTI), fue modificado sin realizar una metaevaluación de los resultados en 20 años. En la evaluación del nuevo PEII nacional (2011), lejos de fomentar la investigación, se evidenció una posición más ideologizada que académica en la modificación del programa anterior. Si para algo pudo servir el nuevo proceso de evaluación, fue para legitimar el programa anterior, pues los resultados arrojaron cifras bastantes similares. Pero con el detrimento de un "genocidio académico" de más de 2500 investigadores que, estando clasificados en el programa anterior, y que se negaron a participar en señal de protesta.

En efecto, el 15 de junio 2011 se publicaron los resultados preliminares del PEI nacional. De los 13.376 que aplicaron solo fueron clasificados 6.472 investigadores. ${ }^{18}$ En todo caso, la eficiencia de la convocatoria al PEI fue del $50 \%$. Respecto al nivel formativo de los clasificados, el 53,3 \% tiene título de doctor. Por universidades, el ranking es el siguiente: Universidad del Zulia (LUZ) con $20 \%$ (1256 investigadores); Universidad de Los Andes (ULA) con el 17\%, y Universidad Central de Venezuela (UCV) con 13\%, lo que representa nuevamente un universo del $50 \%$ entre las 3 instituciones. Por niveles, la discriminación de los investigadores clasificados es: Nivel A: 4642 (nivel inicial), Nivel B: 1801, y Nivel C: 307. (Fuente: Requena, 2011) El SPI-PPI permitía ser el referente nacional de la metaevaluación de la calidad de la investigación de nuestras universidades, dando estímulo a los posgrados, a la conformación de grupos y centros de investigación, a la creación de redes académicas nacionales e internacionales, y propiciando incentivos a las publicaciones científicas en revistas indizadas nacionales e internacionales. Hoy, con el nuevo programa PEII, está por verse cuál será el perfil que desarrollará, teniendo en cuenta que vivimos en una sociedad polarizada a la cual no escapa la comunidad científica. 
Cuadro 1. Tasa de crecimiento promedio anual 1990-2007.

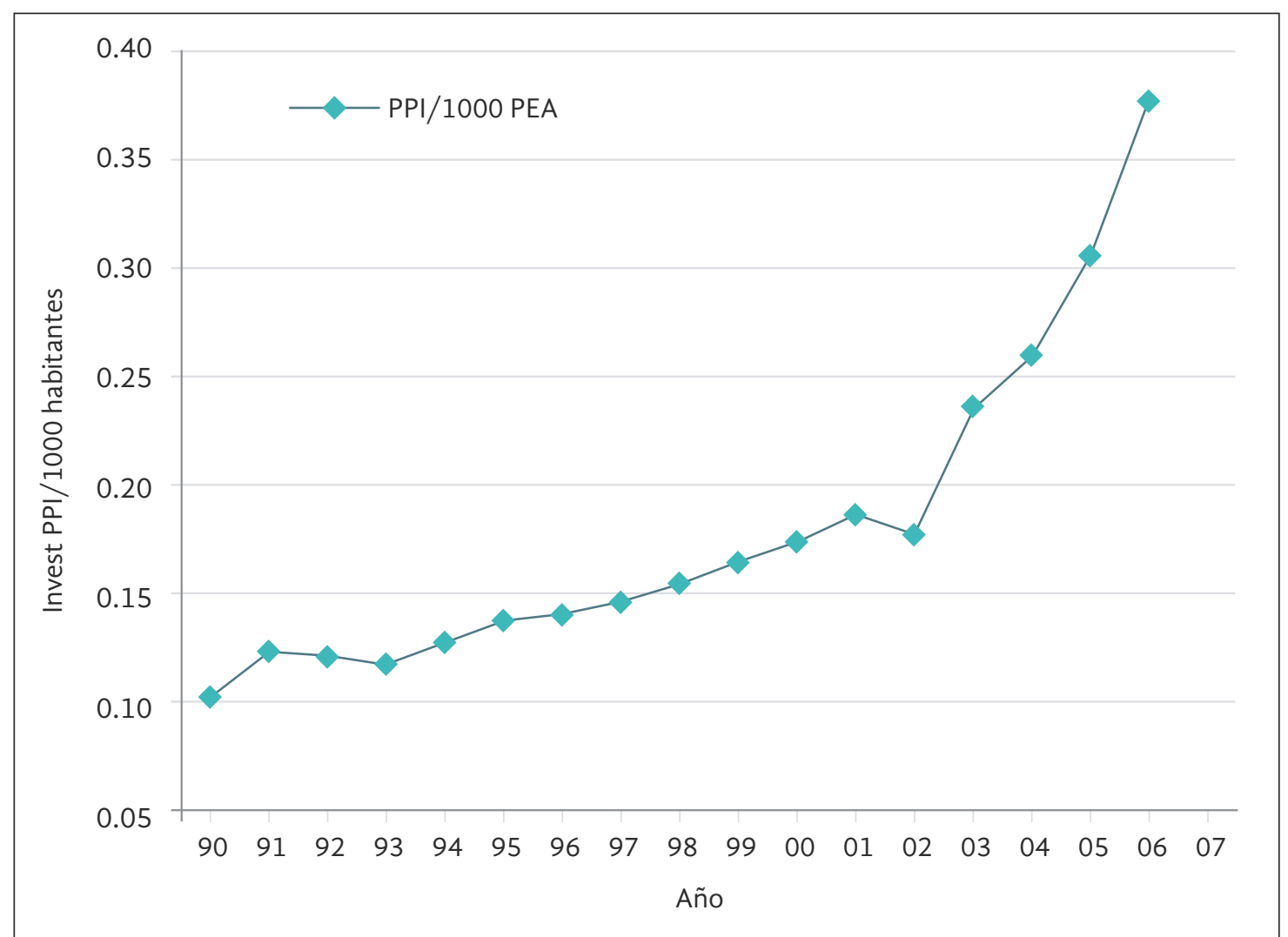

Fuente: Marcano, (2007)

Cuadro 2. Publicaciones en SCI 2002-2006.

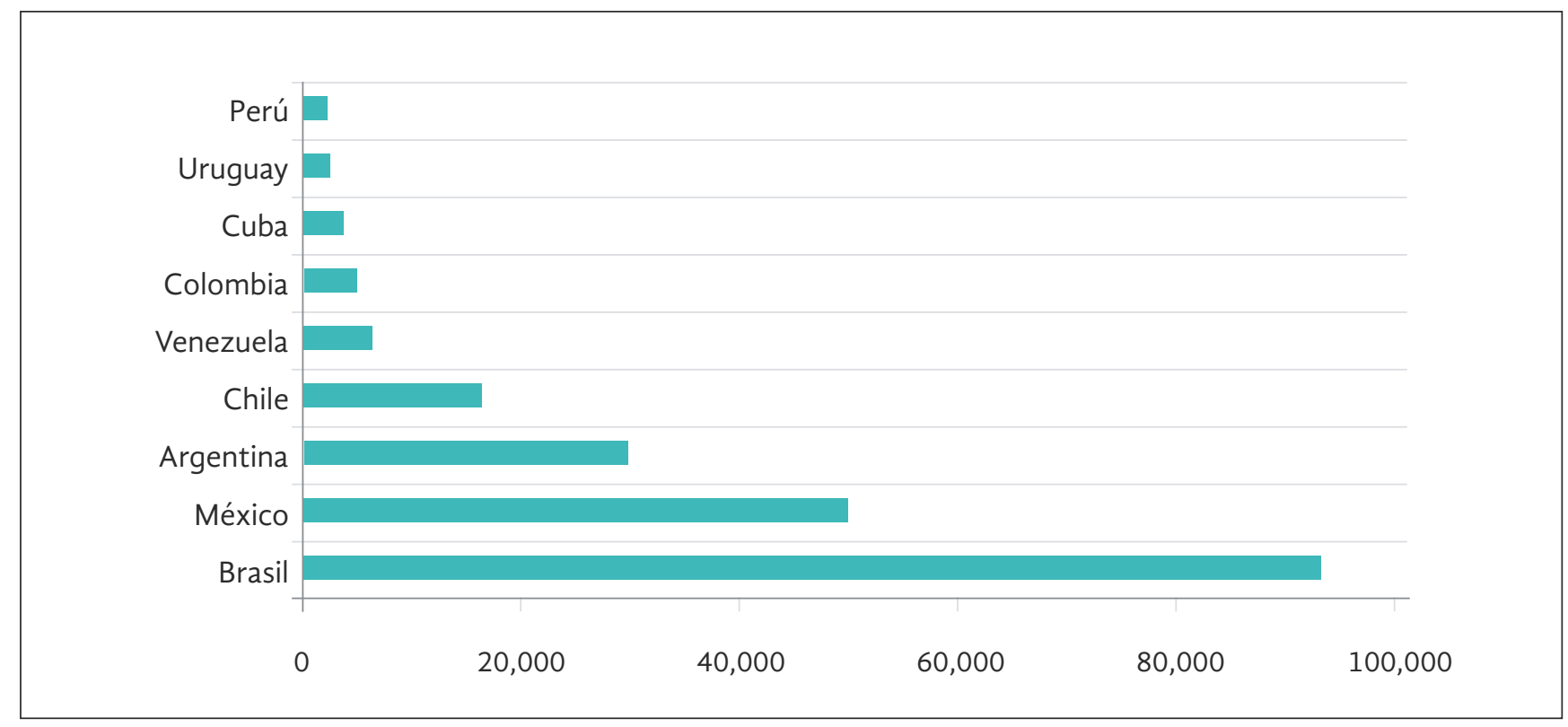

Fuente: Daissy Marcano (2007) 
Cuadro 3. Documentos en el Science Citation Index (SCI) en América Latina y el Caribe (2007).

\begin{tabular}{|c|c|c|}
\hline Fais & Documentes & Percentajes \\
\hline Arzeotina & 6479 & $13.50 \%$ \\
\hline Barbadas & 43 & $0.09 \%$ \\
\hline Blolivis & 201 & $0,42 \%$ \\
\hline Brasl & 23.100 & cs. $15 \%$ \\
\hline Coile & 3.559 & $2,42 \%$ \\
\hline Colonibs & 1239 & $2.58 \%$ \\
\hline Cesta Rica & 399 & Q.20\% \\
\hline Cubu & 748 & 1.546 \\
\hline Repulblica Deminirana & 46 & 0.104 \\
\hline Erwader & $28 ?$ & $0,60 \mathrm{~ns}$ \\
\hline Ceatemala & 301. & $0.21 \%$ \\
\hline Gurgang & 25. & $0,05 \%$ \\
\hline Handaras & 31 & $0.06 \%$ \\
\hline Haiti & 28 & $0.06 \mathrm{~W}$ \\
\hline famaica & 156 & 0.334 \\
\hline Mhice & Bsen & $17,71 \%$ \\
\hline Nicareses & 48. & $0.10 \%$ \\
\hline Fanamb & 369 & arrw \\
\hline Nert & 503 & 1.246 \\
\hline Paracuy & 57 & $0.12 \%$ \\
\hline ES Salvasor & 20 & 0,048 \\
\hline Triaias stahace & 176 & $0.37 \%$ \\
\hline Drupoay & 518 & $1,08 \mathrm{~W}$ \\
\hline Yhineveda & 1.261 & $2.63 \mathrm{w}$ \\
\hline Trtal & 47,993 & $100.00 \%$ \\
\hline
\end{tabular}

Fuente: documentos en SCl-2007, citado por Orlando Albornoz (2012). Las múltiples funciones de la universidad: crear, transferir y compartir conocimiento. San Cristóbal: Fondo editorial Simón Rodríguez, p. 194.

Cuadro 4. Acreditados en el PPI-2007. Distribuídos por área de conocimiento y género.

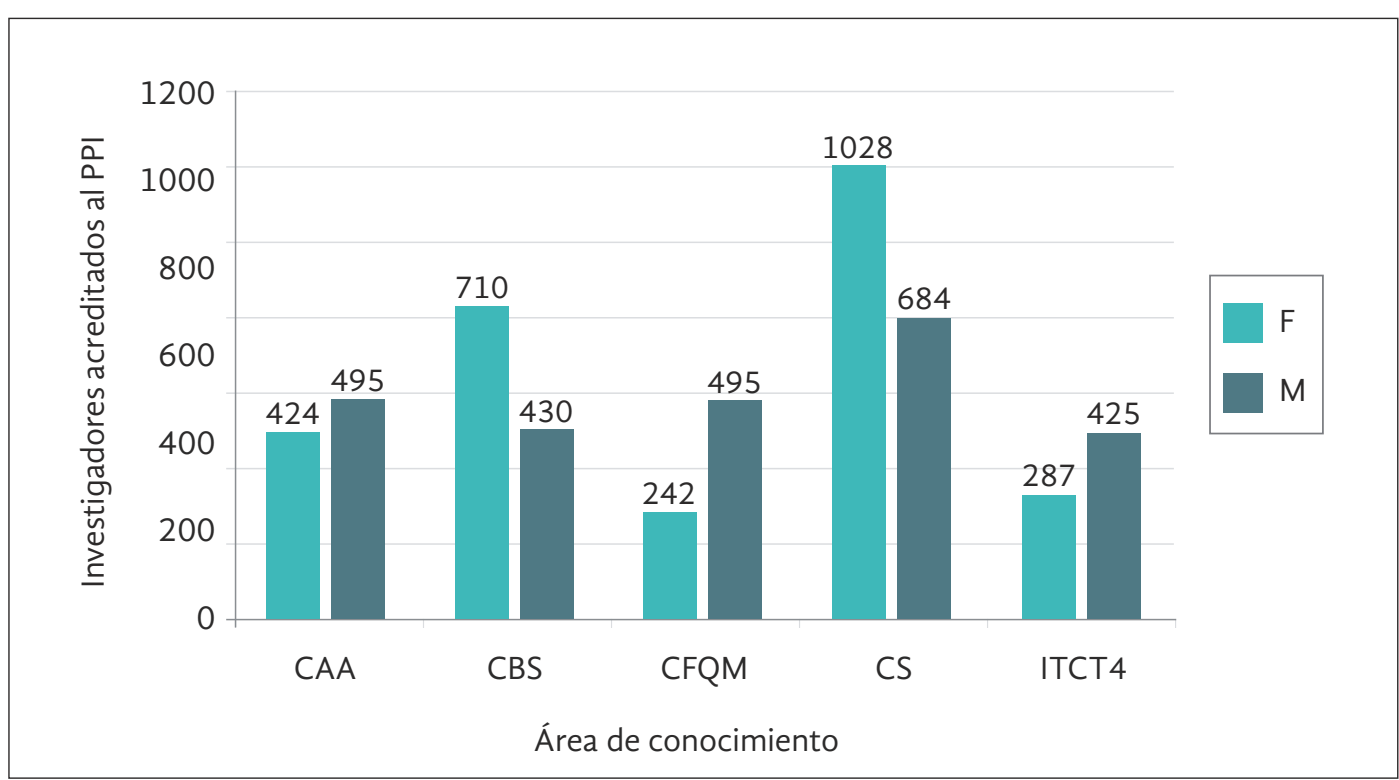

Fuente: Daissy Marcano (2007). 
Cuadro 5. Resultados definitivos del PEI-2011 por área de conocimiento.

\begin{tabular}{|c|c|}
\hline Área de conocimiento & Número total de acreditados \\
\hline Biología y Salud & 1714 \\
\hline Ciencias del Agro, Tecnología de los Alimentos y Ambiente & 1510 \\
\hline Humanidades, Arte y Educación & 1379 \\
\hline Ciencias Económicas y Sociales & 878 \\
\hline Física, Química y Matemática & 699 \\
\hline Ingeniería, Arquitectura y Urbanismo & 968 \\
\hline Ciencias de la Tierra & 157 \\
\hline Energía y Petróleo & 162 \\
\hline Innovación & 263 \\
\hline
\end{tabular}

La web del Fondo Nacional para la Ciencia, la Tecnología y la Innovación - Programa de Estímulo a la Investigación (FONACIT-PEI) señalaba en los datos definitivos del 28 de septiembre de 2011 que el total de investigadores e innovadores es "ocho mil setecientos treinta y ocho (8.738) aspirantes" discriminados de la siguiente manera: "un total de siete mil cuatrocientos setenta y siete (7.477) investigadores y doscientos sesenta y tres (263) innovadores." Los números por sí solo nos pueden confundir. Ante el aparente crecimiento cuantitativo yace un crecimiento negativo en lo cualitativo, pues una tercera parte de los investigadores de más alto nivel no aplicó, al considerar injusta la medida que anulaba al sistema anterior, actuando irresponsablemente y al no reconocer los compromisos con aquellos investigadores que tenían la dieta, en algunos casos, hasta el 2012. Un estudio comparativo por áreas, entre el PPI del 2007 y el PEI 2011 (ver cuadro 4).

Podemos inferir que el área de conocimiento con mayor número de investigadores es Ciencias Sociales, Educación, Humanidades con 1028 investigadores y la de menor productividad de investigadores es el área de Ciencias Físicas, Químicas y Matemáticas.

Los resultados definitivos del PEI-2011 por área de conocimiento señalados en septiembre 2011, pueden consultarse en el cuadro 5.
Curiosamente, Biología y Salud saltaron a liderar, y ciencias sociales pasó al cuarto lugar. Queda pendiente ver el criterio con el cual se evaluó para la consistencia interna de los resultados y considerar que la tercera parte de los investigadores de alto impacto (los que más producen) que estaban en 2007, no participaron en la nueva convocatoria del 2011.

El nuevo programa $\mathrm{PEII}^{19}$ instaurado ha recibido críticas y sobre todo desestimó un trabajo de 20 años elaborado con criterios de excelencia. ${ }^{20} \mathrm{El}$ nuevo PEI quedó estigmatizado como una evaluación ideologizada, que no obstante ser objetiva, pues se aplicó un baremo, tiene el sesgo de la matriz ideológica que acompaña al programa. Aunque la ciencia nunca ha sido neutra (K. P. Feyerabend) era conveniente que se incluyera un equipo de evaluadores heterodoxo ideológicamente y de alto nivel según las clasificaciones de los niveles emérito y PPI IV del sistema anterior para darle mayor objetividad y credibilidad al nuevo programa; pues los evaluadores del PEI, según Requena (2011), en su gran mayoría (62\%), nunca fueron Miembros Activos del extinto Programa de Promoción del Investigador (o PPI); y (51\%) de los evaluadores no lograron ingresar en su debida oportunidad al PPI, el resto (11\%), ni siquiera aplicaron al Programa. El Miembro de mayor jerarquía académica perteneció al Nivel III del PPI. 
Lamentablemente se pudo evidenciar, una vez más, la presencia de la cultura balcánica (Hargreaves y Macmillan 1992), y el criterio confesional de los grupos que profesan en el monopolio de la verdad de las políticas de ciencia y tecnología en Venezuela. La universidad se nutre de la diferencia. En consecuencia, sería un gran error buscar la unanimidad de opinión, ya que "la unanimidad de opinión puede ser apropiada para una iglesia, para las víctimas atemorizadas de algún mito (antiguo o moderno), o para débiles y dispuestos seguidores de algún tirano; la variedad de opiniones es una característica del espíritu objetivo; y un método que estimula la diversidad es el único compatible con una perspectiva humanista" (Feyerabend, 1975, p. 64). ${ }^{21}$
En los últimos años, las convocatorias han mejorado este prejuicio ideológico inicial, y han ampliado la insolvencia inicial, incorporando evaluadores calificados, pero el estigma creado no ha sido superado totalmente. Sin embargo, se continúa tutelando la productividad científica, toda vez que se sigue sacrificando a los investigadores a validar sus publicaciones en los llamados centro de saberes $^{22}$, que no son más que entes burocráticos.

La universidad es el entorno que padece las políticas de Estado $^{23}$ y, la crisis afecta en la formación de talentos, agudizada en los últimos años. ${ }^{24}$

Obviamente el balance que presentamos aquí es preliminar, siempre la historia inmediata tiene sus limitaciones. Pero pensamos que hemos podido dejar ideas para el debate, más que conclusiones.

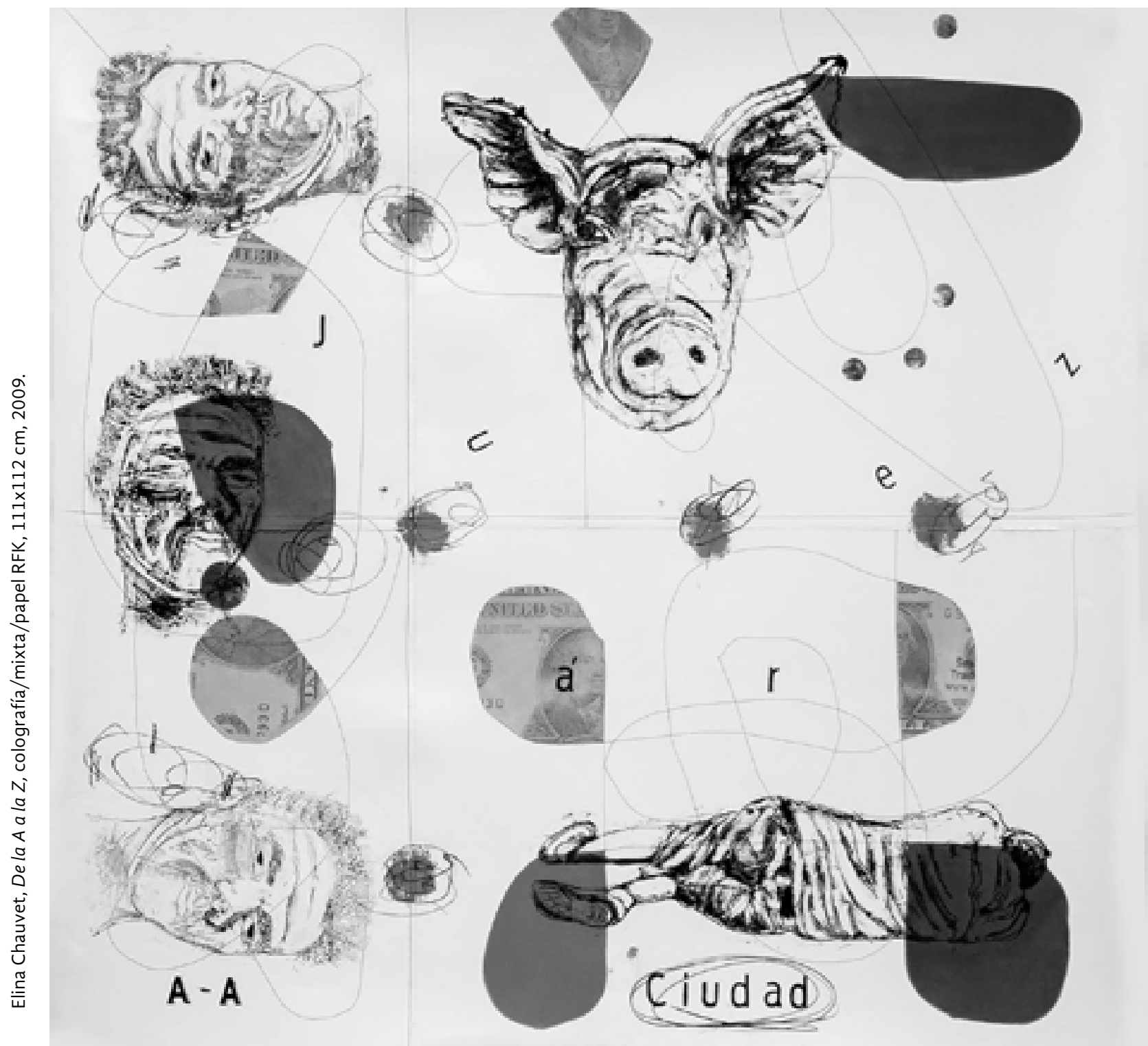




\section{Notas}

1. En el concepto de intelectual se incluye toda una gama de actividades del modo de la producción y de las clases fundamentales, desde los técnicos hasta los creadores científicos. Sin embargo, en términos generales podemos retener que "los intelectuales son los 'empleados' del grupo dominante para el ejercicio de las funciones subalternas de la hegemonía social y del gobierno político [...]" (Gramsci, 1984, 16). Queda claro que los intelectuales en la comprensión gramsciana son los que proyectan la sociedad, y en ese sentido una clase que precisa para su dominio.

2. El término "bachaquero" ha sido acuñado en Venezuela para señalar a aquellas personas que viven mendigando donde hay bienes o productos de primera necesidad para comprarlos y revenderlos en el mercado paralelo, o en el vecino país, a precios no subsidiados. De manera que por "bachaquero del conocimiento" quiero decir la actividad que realizan algunos colegas de mendigar sueldos compensatorios, tickets cestas, becas de los hijos, préstamos blandos, entre otros, para la sobrevivencia sin tener conciencia crítica de las políticas de Estado, que son el problema de fondo; el término entraña un sentido moralizante, porque significa aquel que elige tener una recompensa a costa de su silencio cómplice con las estructuras de dominación.

3. No había cesado el tableteo de las armas automáticas de la Revolución del 18 de octubre de 1945 cuando ya se anunciaba el triunfo alcanzado por el ejército y el pueblo. Esta dupla fue determinante para comprender el desarrollo de dos identidades en la conformación del imaginario político venezolano: "la pasividad del pueblo, su desintegración, el pesimismo sobre su capacidad para ser autor de su propia historia se acabarían con el advenimiento de la Revolución de Octubre. De allí en adelante: no más actitudes contemplativas ante el pasado, quemando incienso ante los retratos de los libertadores y comportándonos como nietos indignos de ellos. Este optimismo será reforzado por otras dos entidades: Pueblo-Partido (AD) y Pueblo-Ejército." (Dávila, 1992, 53). Esa alianza que fue esperanza en 1945, hoy nos profundiza en el más alienante universo mental de la sociedad venezolana, pues ha sido capitalizada en el imaginario colectivo por el actual gobierno para utilizar las fuerzas armadas y manipular al pueblo. Intentando presentar una unión ficticia, per se de dos realidades que se oponen entre sí.

4. Ese nacionalismo metodológico ha sido denunciado por Ulrich Beck Ulrich (2004).

5. Tinoco, el estudiante de la UNET a quien se le cegó la vida en 2014, todavía sigue entre nosotros reclamando en nuestra memoria colectiva su derecho a la disidencia.

6. Olivier Fressard.

7. Simón Bolivar (1983) Obras Completas. Tomo III, 720.

8. Clausewitz. Citado por Huntington, 63.

9. Aunque luego cambiaron de nombre a Educación Universitaria, en ese nominalismo exagerado.

10. Iván de la Vega comentó que Venezuela es el principal emisor de personal altamente calificado e indicó que factores como la falta de competitividad de los salarios y la inseguridad son puntos determinantes al decidir dejar el territorio venezolano. De la Vega precisó que el 51\% de los venezolanos que han ingresado a Estados Unidos son al menos licenciados, mientras que en el caso de España la cifra aumenta a 53\%, reseñó que la emigración no forma parte de la cultura del venezolano, sin embargo el deterioro de las condiciones generales del país ha favorecido que Venezuela se convierta en emisor de emigrantes cuando fue durante muchos años receptor. En "De la Vega: casi dos millones de personas han emigrado de Venezuela".
Recuperado de: http://www.bancaynegocios.com/de-la-vega-casidos-millones-de-personas-han-emigrado-de-venezuela/

11. Adelantos de esta línea de investigación se encuentran en: José Pascual Mora García (2014) "Las Políticas Públicas en la Formación del Profesorado en Venezuela: (1999-2011)”, en José Rubén Lima Jardilino et Al (Edit.) Formação e Políticas Públicas na Educação: Profissão e Condição Docente. En: Brasil: Paco Editorial -UFOuro Preto, ISBN: 978-85-8148-755-7, p.41- 65.

12.Los Consejos de Desarrollo Científico Humanístico Tecnológico (CDCHT) en las universidades nacionales de Venezuela son los entes académicos que gerencian la investigación.

13. Lo cierto es que los programas de incentivos a la investigación fueron reducidos drásticamente; un ejemplo en esta dirección nos lo suministran los datos de financiamiento a los investigadores para presentar sus resultados en las comunidades científicas internacionales en 2011, y que en el caso, de la Universidad de Los Andes se redujo a la mínima expresión a raíz del tutelaje ejercido desde la Vicepresidencia de la República, en un todo de acuerdo con lo establecido en el Decreto Presidencial $\mathrm{N}^{\circ}$ 6649. Este tutelaje dañó considerablemente la producción de conocimientos en la universidad al tener que pasar por su humillante autorización, como si fuera un organismo académico; destruyendo el desarrollo de la productividad en redes y el cosmopolitismo en las trayectorias de los investigadores.

14. Fallida en tanto fue derogada por el presidente Hugo Chávez, en principio, pero en la práctica se comenzó a aplicar de manera "blanda", a partir de políticas de Estado que de facto ejercían el "espíritu" de aquella.

15. En nuestro trabajo seguimos los criterios de Daissy Marcano y Mauricio Phelan (2009). Al respecto recomiendo revisar el interesante trabajo de Daissy Marcano y Mauricio Phelan(2009) "Evolución y desarrollo del Programa de Promoción al Investigador en Venezuela", Interciencia, Vol. 34, $\mathrm{n}^{\circ}$ 1, pp. 17-24. Igualmente recomiendo como un soporte documental más amplio los siguientes:

De Venazi, Francisco (1980). Necesidad de un sistema de reconocimiento para los investigadores universitarios. Boletín $\mathrm{N}^{\circ} 12,30 / 06 / 1980$. APIU. Caracas, Venezuela.

De Venazi, Francisco (1980). Sistema de Reconocimiento de los investigadores activos de la Universidad Central de Venezuela: Boletín No 14, 15/11/1980. APIU. Caracas. Venezuela.

Daissy Marcano (2006). Trayectoria del Programa de Promoción del Investigador en Venezuela. En Conocimiento y Necesidades de las Sociedades Latinoamericanas. IVIC. Caracas, Venezuela, pp. 127-132.

Hebe Vessuri (1996) "La calidad de la investigación en Venezuela: Elementos para el debate en torno al Programa de Promoción del Investigador." Interciencia, Vol. 21: Venezuela, pp. 98-102.

16. Daissy Marcano y Mauricio Phelan (2009) Evolución y desarrollo del programa de promoción del investigador en Venezuela. INCI [online]. 2009, vol.34, n.1, pp. 17-24. ISSN 0378-1844.

17. Cfr. MARCANO, Daissy y Mauricio PHELAN (2009) "Evolución y desarrollo del Programa de Promoción al Investigador en Venezuela”, en Interciencia, Vol. 34, n 1 . p. 23.

18. Jaime Requena. Diario Tal Cual, 20 de junio de 2011.

19. María Pilar García Gaudilla (2011) "El PEI: negación de la Universidad autónoma y creadora "en http://presidencia.asovac.org/ el-pei-negacion-de-la-universidad-autonoma-y-creadora/ 
20. El nuevo PEII quedó estigmatizado como una evaluación ideologizada, que no obstante ser objetiva_pues se aplicó un baremo_tiene el sesgo de la matriz ideológica que acompaña al programa. Aunque la ciencia nunca ha sido neutra (K. P. Feyerabend) era conveniente que se incluyera un equipo de evaluadores heterodoxo ideológicamente y de alto nivel según las clasificaciones de los niveles emérito y PPI IV del sistema anterior para darle mayor objetividad y credibilidad al nuevo programa; pues los evaluadores del PEII según Jaime Requena (2011) en Diario Tal Cual, 20 de junio de 2011; en su gran mayoría (62\%), nunca fueron Miembros Activos del extinto Programa de Promoción del Investigador (o PPI); y (51\%) de los evaluadores no lograron ingresar en su debida oportunidad al PPI, el resto (11\%), ni siquiera aplicaron al Programa, el Miembro de mayor jerarquía académica perteneció al Nivel III del PPI. Cfr. Jaime Requena (2011) Ciencia y poder, eco de sus conflictos. San Cristóbal. Fondo Editorial Simón Rodríguez. San Cristóbal. P. 19

21. Karl P. Feyerabend (1975). Cómo ser un buen empirista: petición de tolerancia en asuntos epistemológicos, Nidditch, P. H. (Coord) Filosofía de la ciencia. México:Breviarios. F.C.E., p. 64.

22.Esos centros de saberes los encontramos en la Universidad Bolivariana de Venezuela. A partir del 2016, se creó el Consejo Nacional de Producción y Recreación de Saberes 2016. Ver: http://www.ubv.
edu.ve/content/blog/consejo-nacional-de-producci\%C3\%B3n-yrecreaci\%C3\%B3n-de-saberes-2016

23. Orlando Albornoz (2012) La Universidad ¿Reforma o experimento?; El discurso académico contemporáneo según las perspectivas de los organismos internacionales: los aprendizajes para la universidad venezolana y latinoamericana. Caracas: Instituto Internacional de la Unesco para la Educación Superior en América Latina y el Caribe, IESALC. Albornoz ensaya su respuesta a esta interrogante en función de su participación en el escenario internacional de las universidades, especialmente por su participación en la 14ta Conferencia de la Asociación Internacional de Universidades (San Juan, Puerto Rico, 27 a 30 de noviembre de 2012) y en la Conferencia Going Gobal 2013 (Dubái, Emiratos Árabes Unidos, 4 a 6 de marzo de 2013).

24.Hugo Prieto (2016). “Orlando Albornoz: En 10 años hemos perdido el 28 por ciento de nuestro talento". Recuperado de http://prodavinci. com/2016/08/28/actualidad/orlando-albornoz-en-10-anos-hemosperdido-el-28-por-ciento-de-nuestro-talento-por-hugo-prieto/

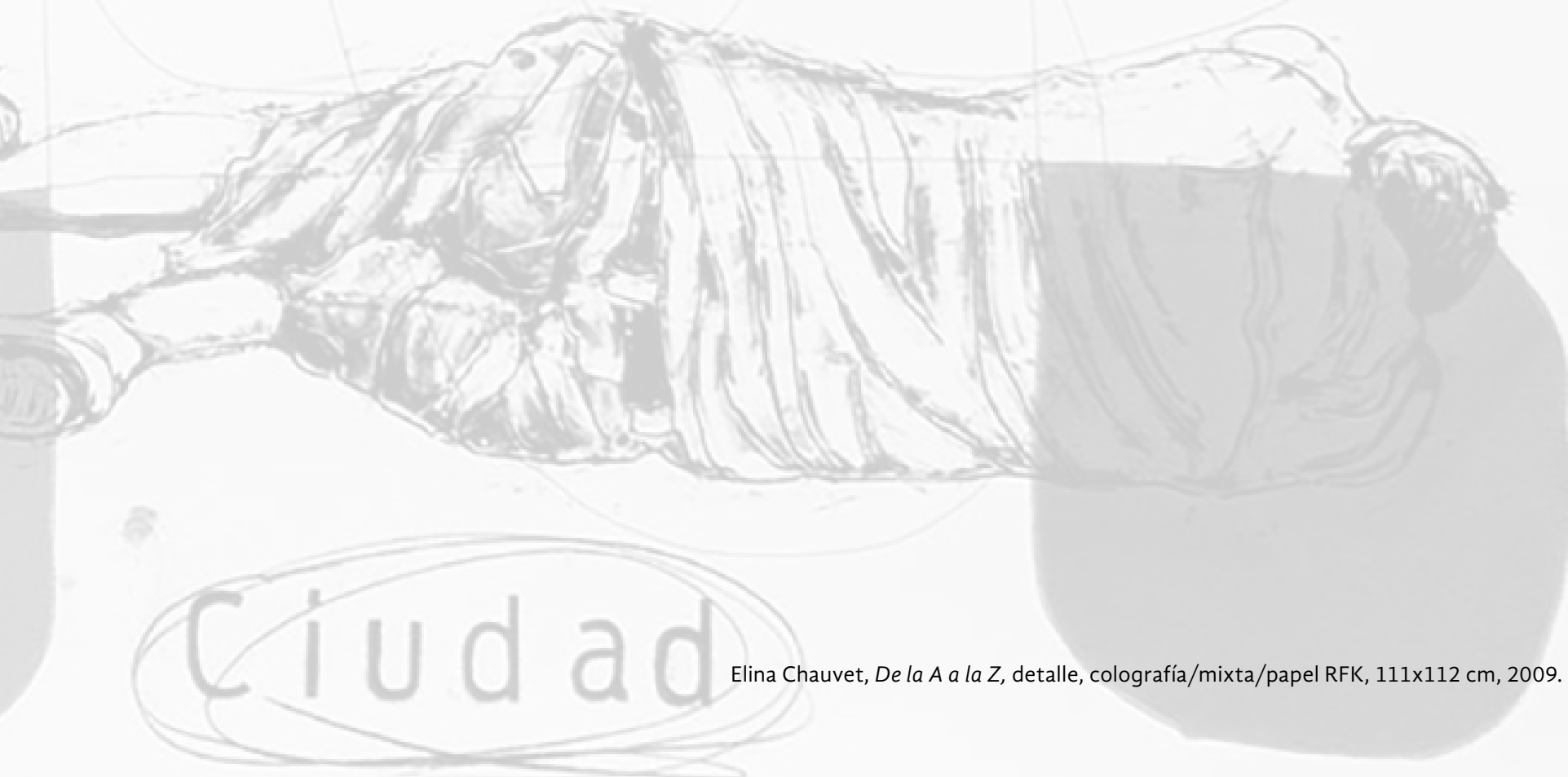




\section{Bibliografía}

Boff, Leonardo (1980). Ternura y vigor. Barcelona: Ediciones Paulinas.

Colom González, F. (2005). Relatos de nación. (La construcción de las identidades nacionales en el mundo hispánico). España: Iberoamericana.

Dávila, Luis Ricardo (1992). Imaginario político venezolano. Caracas: Alfadil.

Dávila, Luis Ricardo (2005). Independencia e insuficiencia en la construcción de la nación venezolana. En F. Colom González, Relatos de nación. (La construcción de las identidades nacionales en el mundo hispánico). España: Iberoamericana.

Dávila, Luis Ricardo (2005). El imaginario petrolero (petróleo e identidades nacionales en Venezuela). En Martín Fechilla, J. y Yolanda Arnal (Comp.), Petróleo nuestro y ajeno. La ilusión de Modernidad. Caracas: UCV.

Dávila, Luis Ricardo (2006). Momentos fundacionales del imaginario democrático venezolano. En D. Carrera Damas, G. Leal Curiel, C. Lomné, G, y F. Martínez (Comp.), Mitos políticos en las Sociedades Andinas. Orígenes, invenciones y ficciones. Caracas: EquinoccioUniversidad de Marne-la-Vallée, Instituto Francés de Estudios Andinos.

Foucault, M. (1980). Microfísica del poder. La Piqueta: La Piqueta.

Gramsci, A. (1984). Los intelectuales y la organización de la cultura. Buenos Aires: Nueva Visión.

López Pedraza, R. (2000). Ansiedad Cultural. Acea: Caracas.

Le Goff, J. (1991). El Orden de la Memoria. Paidós: Barcelona.

Mora García, José Pascual (1997). La crisis del saber académico y la investigación en la atmósfera postmoderna. Investigación, ( $\left.\mathrm{N}^{\circ} 3\right)$.

Mora García, José Pascual (2000). Análisis bibliométrico de la productividad de los profesores en la Universidad de Los Andes-Táchira, estudio de caso: Área de historia de la educación. (1993-1998.) Tesina mimeografiada, presentada para optar al DEA en el programa de Doctorado de la Universidad Rovira i Virgilli. Tarragona, España.

Mora García, José Pascual (2001). La metaevaluación de la investigación. Investigación, (núm. 4).

Mora García, José Pascual (2001). La universidad a Debate. En E. López (Coord.), Una Visión de la transformación universitaria. San Cristóbal, Universidad de Los Andes-Táchira: Grupo Greco.

Mora García, José Pascual (2002-2005). Proyecto de Investigación auspiciado por el CDCHT ULA: "Análisis Bibliométrico de las Comunidades Discursivas de Historia de la Educación en América Latina. Estudio de Caso: Venezuela." Código: NUTA-H-170-0206-B. Aprobado por el Directorio del CDCHT en la reunión 06-02 de fecha 12/12/02. Entregado informe final 2005, con mención doble productividad.

Mora García, José Pascual (2006). El neo-nacionalismo bolivariano... Aldea Mundo, Revista sobre Fronteras e Integración, año 11 (núm. 21).

Mora García, José Pascual (2006). Imaginario Social Bolivariano. San Cristóbal: Editorial Simón Rodríguez.

Mora García, José Pascual (2008). Rómulo Betancourt: forjador del imaginario democrático venezolano. Tiempo y Espacio, volumen 18 (núm. 49).

Mora García, José Pascual (2009). Comunidades Discursivas de Historia de la Educación, Estudio de caso: Venezuela (1998-2008). Tarragona: URV.
Mora García, José Pascual (2009). Una mirada desde la historia de la educación a la nueva Ley Orgánica de Educación: consistencias e inconsistencias epistemológicas. Educere, volumen 13 (fasc.46), pp. $829-842$.

Mora García, José Pascual (2011). La Ley de Educación Universitaria-2010, una mirada desde el punto de vista de la filosofía de la educación. Educere (núm. 50), pp. 789-800.

Mora García, José Pascual (2012). El Crecimiento Negativo Cualitativo de los Investigadores. Fermentum: Revista Venezolana de Sociología y Antropología, vol. 22 (fasc.64), pp. 255 - 273.

Mora García, José Pascual (2012). La cultura de paz y la racionalidad dialógica gadameriana: una mirada sobre la filosofía de la paz en Rotary. Revista Heurística, (núm. 15).

Mora García, José Pascual (2012). La investigación tutelada en el CDCHTA-ULA. Educere, volumen 16 (fasc. 53), p.190 - 191.

Mora García, José Pascual (2014). La indexación de las revistas de educación e historia de la educación, un problema geopolítico, bioético y epistemológico. Suma+Paz (núm. 4), pp. 39-50. Recuperado de http://revistas_electronicas.unicundi.edu.co/index. php/Suma_paz

Mora García, José Pascual (2017). El síndrome "Solano", La Nación. Recuperado de: http://lanacionweb.com/columnas/opinion/ el-sindrome-solano/

Mora García, José Pascual. El “Cordobazo” tachirense y la Conferencia de Paz. La Nación. Recuperado de: http://www.lanacion.com.ve/ columnas/opinion/el-cordobazo-tachirense-y-la-conferenciade-paz/ Alianza Editorial.

Otero, Marlene (2014). "Docentes de SHELA y ULA-Táchira manifestaron por desaparecidos de México". Recuperado de: http://www. prensa.ula.ve/2014/11/17/docentes-de-shela-y-ula-tachiramanifestaron-por-desaparecidos-de-mexico/

Sartre, Jean Paul (2007). El existencialismo es un humanismo. Barcelona: Edhasa.

Ulrich, B. (2004). Poder y contrapoder en la era global. La nueva economía política mundial. Barcelona: Paidós. 